\title{
Autoregressive Moving Average Models of Conifer Crown Profiles
}

\begin{abstract}
Samantha J. GILL and Gregory S. BIGING
A time-series autoregressive moving average (ARMA) approach was used to develop stochastic models of tree crown profiles for five conifer species of the Sierran mixed conifer habitat type. Models consisted of three components: (1) a polynomial trend; (2) an ARMA model; and (3) random error. A Bayesian information criterion was used to evaluate alternative models. It was found that $70 \%$ of the crown profiles could be modeled using first-order ARMA [AR(1) or MA(1)] models, and that an additional $25 \%$ could be modeled using a white noise model $[(\mathrm{AR}(0)]$. When the coefficients of the ARMA models were statistically significant, the models proved to be both visually and statistically an improvement over the polynomial trend (a Euclidean model). A binary classification system was used to determine if model type was related to tree or stand characteristics. Using this classification we found that it was possible to relate the appropriate model type to forest tree size and forest stand density with acceptable accuracy.
\end{abstract}

\section{INTRODUCTION}

Models of tree crowns are important in many aspects of ecology because the crown contains the photosynthetically active portion of the tree. The amount of carbohydrates produced by a tree depends primarily on the size of the crown or crown leaf surface area and the capacity of the roots to absorb water and mineral nutrients, synthesize certain hormones, and translocate these components to the foliage (Assmann 1970; Dong and Kramer 1986; and Kramer 1988). The geometric space occupied by the crown (crown volume) is also highly correlated with growth (Biging and Dobbertin 1992, 1995; and Mitchell 1975) mainly because correlation between crown volume and crown surface area is near unity. 
Models of tree crowns are used in several fields of resource management. For instance, Biging and Dobbertin $(1992,1995)$ used models of tree crowns in their studies of tree competition in mixed conifers. Crown models have been used to predict wildlife habitat (Moeur 1981) and as a predictor of bird abundance in the lower canopy (Morrison, Timossi, and With 1987). Crown models have also been used in studies of within-tree and betweentree shading of solar radiation within a forest canopy (Kuuluvainen and Pukkula 1989). Crown models are also useful in forest stand visualization programs that allow for threedimensional display and analysis of spatial forestry data (Burkhart 1992: McGaughey 1998; Nagel 2001; and Pretzsch 1993).

The most commonly employed method for modeling tree crowns involves the estimation of simple Euclidean geometric shapes using ordinary least squares. For example, Biging and Wensel (1990) used a parabolic model for modeling volume and surface area of conifer species in California. Mitchell (1975) also used a parabolic model for crowns in his simulation of Douglas-fir trees. Conic models have been used to model young Douglas-fir trees (Mohren, Gerwen, and Spitters 1984), but in the same study a parabolic model was used for mature trees. Baldwin and Paterson (1997) used a flexible polynomial model for the exterior of the crown and a conic model for the inner defoliated area of the crown. Sometimes, the crown is modeled as a combination of geometric forms, such as a conic form for the top portion of the crown and a parabolic form for the lower portion of the crown (Pretzsch 1992). Hann (1999) used an adjustable model that could take on many polynomial forms to model Douglas-fir trees. Instead of using only a couple of Euclidean shapes, Mawson, Thomas, and DeGraff (1976) visually compared individual tree crowns to 15 different Euclidean geometric shapes. Selecting the most appropriate crown form, field measurements of height-to-crown base and the radius at the height-to-crown base (radius for a circle, major and minor axis for an ellipse, or base and height of a triangle) were taken to compute crown volume. Instead of using ordinary least squares, Nepal, Somers, and Caudill (1996) used stochastic frontier models to fit variable crown forms.

An alternative to modeling the exterior of tree crowns is to model the branching architecture (Maguire, Moeur, and Bennett 1994; Colin and Houllier 1992), and branch length (Gavrikov and Karlin 1992; Ford, Avery, and Ford 1990; Ford and Ford 1990). In addition to models of branch angle and branch length, models of the horizontal distribution of foliage within branches have been developed (Kershaw and Maguire 1996). Using models of branch position and diameter with the models of branch length, it is possible to simulate entire tree crowns. Fractal geometry has also been used for describing tree crowns (Corona 1991; Zeide and Gresham 1991; Zeide and Pfeifer 1991; Zeide 1998). A great deal of information is needed to parameterize models using either crown architecture or fractals.

To capture the inherent variability of tree crown profiles Doruska and Mays (1998) used nonparametric regression, but with small datasets. Biging and Gill (1997) and Gill and Biging (2002) employed time-series models with four to seven times more data for individual trees than was used in Doruska and Mays' study. Time-series models can be used with autocorrelated data to estimate equations that explain how the "current" observations are related to "past" observations and/or "past" disturbances. Other uses of time-series analy- 
sis in forestry studies, include tree-ring chronologies (Monserud 1986), crown increment (Pretzsch 1992), or relating climate to tree growth (Jordan and Lockaby 1990).

The models developed by Biging and Gill (1997) were based on a small number of individuals (31 trees), while the research reported here uses similar techniques on a significantly larger set of trees. Because of the size of the dataset used by Biging and Gill (1997), it was not possible to examine the relationship between ARMA model and tree characteristics, nor could it be inferred that these results were representative of mixed conifer forests in California.

The primary objective of this research was to investigate if time-series models are an improvement over using simple polynomial trend models to characterize the crown profiles of the major conifer species throughout northern California's Sierran mixed conifer habitat type. Tremendous diversity in species composition and tree sizes as well as differences in forest densities characterize these forests. Thus, the secondary objective was to examine the data to find if the order of the ARMA model was related to observable tree characteristics or forest stand characteristics. After deciding the order of the ARMA model, the trend and ARMA coefficients are needed to simulate individual tree crown profiles. This final predictive exercise will be presented in another study.

\section{DATA}

The data for this research were collected from the Sierran mixed conifer habitat type. The Sierran mixed conifer habitat type consists of white fir (Abies concolor (Gord. \& Glend.), Douglas-fir (Pseudotsuga menziesii (Mirb.) Franco), ponderosa pine (Pinus ponderosa (Laws.)), sugar pine (Pinus lambertina Doubl.), incense-cedar (Calocedrus decurrens (Torr.)), and California black oak (Quercus kelloggii (Newb.)) For this research, ponderosa pine, sugar pine, white fir, Douglas-fir, and incense cedar were sampled.

In order to measure the radii of tree crowns, it was necessary to be able to see the entire profile of the crown from at least one perspective. The profile of a tree crown can be conceptualized by mentally tracing the outside edge of a tree crown (Figure 1, panel 1a). It is actually a generalization of a vertical slice through the crown and passing through the center of the bole of the tree. If the stand has a closed canopy, it is hard to clearly distinguish the profile of individual trees because the branches from adjacent trees overlap one another. Because of the difficulties of measuring crown profiles in a closed canopy, it was not possible to follow a standard sampling protocol such as simple random sampling or systematic sampling. Trees were instead selected from among the target groups (described below) using purposive sampling in recently thinned (within three years) stands or in stands where clearcuts were done earlier in the same year, but small patches of trees were left. Within these harvested stands, trees were purposively sampled over a range of sizes and stand densities. These commercial forest stands were managed in a myriad of ways, with many of them being managed since stand conception (often planting). These commercial forests could be different from natural areas, but because of the difficulties in sampling tree crowns, it was not possible to sample in natural areas. 


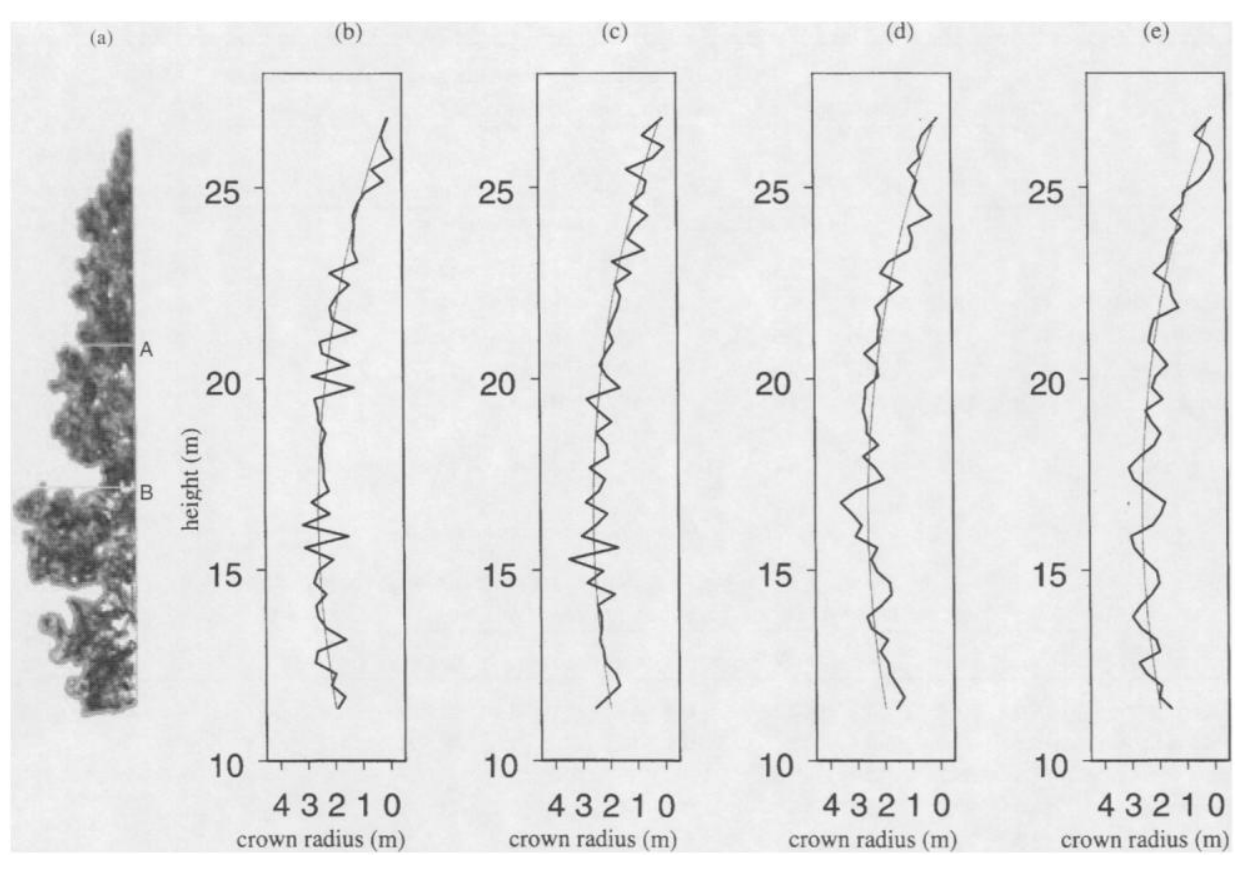

Figure 1. Panel la is a scanned photograph of the left half of a ponderosa pine tree crown. The tree is $50.8 \mathrm{~cm}$ in $D B H, 26.8 \mathrm{~m}$ tall and has a crown length of $14.6 \mathrm{~m}$. Panels $1 \mathrm{~b}$ and $1 \mathrm{c}$ are crown simulations using an MA(1) process. Panels $1 d$ and le depict crown simulations using an AR(1) process. All four simulations also include the quadratic trend line. The MA(1) plus trend is: crrad $_{t}=-0.569 u_{t-1}+u_{t}+\left(-3.61+0.75 t+0.02 t^{2}\right)$. The $A R(1)$ model plus trend is: crrad $_{t}=0.574\left(\right.$ residual $\left._{t-1}\right)+u_{t}+\left(-3.61+0.75 t+0.02 t^{2}\right)$; where crrad $_{t}=$ crown radius $(m)$ is evaluated at height above ground $(m)=t, u=$ white noise series with $\sigma^{2}=0.139$ for the $M A(1)$ simulation 0.1412 for the $A R(1)$ model.

A sampling design was established to ensure that a wide range of tree sizes was sampled from a range of stand densities. For collecting data of the Sierran mixed conifer habitat type two species groups, five before harvest density levels, and four height classes were considered. The two species groups were pines (sugar or Ponderosa) and firs (Douglas or white). The density levels consisted of the following basal area (ba) levels:

1. ba $\leq 29.8 \mathrm{~m}^{2} / \mathrm{ha}\left(130 \mathrm{ft}^{2} / \mathrm{ac}\right)$;

2. $29.8 \mathrm{~m}^{2} / \mathrm{ha}\left(130 \mathrm{ft}^{2} / \mathrm{ac}\right) \leq \mathrm{ba} \leq 36.7 \mathrm{~m}^{2} / \mathrm{ha}\left(160 \mathrm{ft}^{2} / \mathrm{ac}\right)$;

3. $36.7 \mathrm{~m}^{2} / \mathrm{ha}\left(160 \mathrm{ft}^{2} / \mathrm{ac}\right) \leq \mathrm{ba} \leq 45.9 \mathrm{~m}^{2} / \mathrm{ha}\left(200 \mathrm{ft}^{2} / \mathrm{ac}\right)$;

4. $45.9 \mathrm{~m}^{2} / \mathrm{ha}\left(200 \mathrm{ft}^{2} / \mathrm{ac}\right) \leq \mathrm{ba} \leq 57.4 \mathrm{~m}^{2} / \mathrm{ha}\left(250 \mathrm{ft}^{2} / \mathrm{ac}\right)$; and

5. ba $\geq 57.4 \mathrm{~m}^{2} / \mathrm{ha}\left(250 \mathrm{ft}^{2} / \mathrm{ac}\right)$.

The height classes (htc) used were:

1. htc $\leq 18.3 \mathrm{~m}(60 \mathrm{ft})$;

2. $18.3 \mathrm{~m}(60 \mathrm{ft}) \leq \mathrm{htc} \leq 27.4 \mathrm{~m}(90 \mathrm{ft})$;

3. $27.4 \mathrm{~m}(90 \mathrm{ft}) \leq \mathrm{htc} \leq 36.6(120 \mathrm{ft})$; and

4. htc $\geq 36.6 \mathrm{~m}(120 \mathrm{ft})$.

From each of the 40 species group-density-height combination levels, an attempt was made to collect information on four to six trees. Roughly equal numbers of each species within a 
Table 1. Summary Statistics of Trees Used in This Study

\begin{tabular}{|c|c|c|c|c|c|c|c|c|c|c|c|c|}
\hline \multirow[b]{2}{*}{ species } & \multicolumn{2}{|c|}{$D B H(\mathrm{~cm})$} & \multicolumn{2}{|c|}{ total height $(m)$} & \multicolumn{2}{|c|}{$\begin{array}{l}\text { Height-to-crown } \\
\text { base (hcb) }(m)\end{array}$} & \multicolumn{2}{|c|}{$\begin{array}{l}\text { stand basal area } \\
\qquad\left(m^{2} / h a\right)\end{array}$} & \multicolumn{2}{|c|}{$\begin{array}{c}\text { crown radius at } \\
h c b(m)\end{array}$} & \multirow{2}{*}{$\begin{array}{l}\text { no. of } \\
\text { trees }\end{array}$} & \multirow{2}{*}{$\begin{array}{l}\text { no. of crown } \\
\text { profile series }\end{array}$} \\
\hline & mean & st. dev & mean & st. dev & mean & st. dev & mean & st. dev & mean & st. dev & & \\
\hline \multicolumn{13}{|c|}{ Table 1a. Mean and standard deviations } \\
\hline Douglas-fir & 44.5 & 18.0 & 23.2 & 8.6 & 7.6 & 5.4 & 49.71 & 14.18 & 3.3 & 1.2 & 24 & 29 \\
\hline incense cedar & 44.4 & 18.5 & 19.1 & 6.3 & 5.7 & 3.4 & 51.05 & 16.11 & 2.9 & 0.9 & 30 & 35 \\
\hline ponderosa pine & 45.7 & 17.0 & 26.6 & 9.5 & 10.4 & 5.3 & 46.64 & 14.12 & 2.6 & 0.9 & 47 & 63 \\
\hline sugar pine & 47.7 & 22.4 & 26.3 & 10.0 & 11.9 & 6.1 & 65.37 & 13.77 & 3.0 & 1.2 & 35 & 43 \\
\hline white fir & 39.9 & 20.1 & 23.7 & 9.9 & 8.7 & 6.0 & 47.14 & 12.03 & 2.7 & 1.1 & 43 & 49 \\
\hline all conifers & 44.2 & 19.3 & 24.1 & 9.4 & 9.1 & 5.7 & 50.94 & 13.91 & 2.8 & 1.0 & 179 & 219 \\
\hline \multicolumn{13}{|c|}{ Table $1 b$. Minimums and maximums } \\
\hline & \multicolumn{2}{|c|}{$D B H(\mathrm{~cm})$} & \multicolumn{2}{|c|}{ total height $(m)$} & \multicolumn{2}{|c|}{$\begin{array}{l}\text { Height-to-crown } \\
\text { base (hcb) (m) }\end{array}$} & \multicolumn{2}{|c|}{$\begin{array}{c}\text { stand basal area } \\
\left(m^{2} / h a\right) \\
\end{array}$} & \multicolumn{2}{|c|}{$\begin{array}{c}\text { crown radius at } \\
h c b(m)\end{array}$} & & \\
\hline species & $\min$ & $\max$ & $\min$ & $\max$ & $\min$ & $\max$ & $\min$ & $\max$ & $\min$ & $\max$ & & \\
\hline Douglas-fir & 14.0 & 87.9 & 8.2 & 40.2 & 0 & 17.1 & 19.38 & 71.22 & 1.5 & 6.4 & & \\
\hline incense cedar & 16.5 & 92.5 & 6.4 & 33.8 & 0 & 12.8 & 25.79 & 74.89 & 1.5 & 6.4 & & \\
\hline ponderosa pine & 17.5 & 85.3 & 10.1 & 40.8 & 1.2 & 20.7 & 25.79 & 74.89 & 1.2 & 4.9 & & \\
\hline sugar pine & 14.0 & 90.7 & 8.8 & 48.5 & 0 & 24.7 & 33.66 & 71.22 & 1.2 & 5.2 & & \\
\hline white fir & 12.7 & 93.0 & 7.3 & 45.7 & 0 & 20.7 & 25.79 & 74.89 & 1.5 & 5.8 & & \\
\hline all conifers & 12.7 & 93.0 & 6.4 & 48.5 & 0 & 24.7 & 19.38 & 74.89 & 1.2 & 6.4 & & \\
\hline
\end{tabular}

species group were sampled. Incense-cedar was not part of the sampling design, but it was opportunistically sampled from each of the stands. Deviations from this design occurred at the lowest density level because stands were not often thinned at this density, and natural stands of this density were not open enough to adequately distinguish different tree crowns. Also, there were problems with photographing the taller trees. Since the camera must remain level, to photograph a tall tree, one must be rather far (up to 70-80 m) from the tree even using a 35-210 mm lens, and this often resulted in obstructions (usually other trees) between the observer and the tree of interest. A wide range of tree sizes and stand densities along with a somewhat even distribution of species was achieved (refer to Table 1).

Every tree in the study was measured for diameter, height, average height-to-crown base, lowest live branch, and radius of the crown at the height-to-crown base in the direction for which the crown profile was measured and photographed. In addition, a density measure, forest stand basal area (cross sectional area $\left(\mathrm{m}^{2} / \mathrm{ha}\right)$ of tree diameters measured at 1.3 $\mathrm{m}$ above ground) before harvest was measured (Gill 1997). Each sampled tree was also photographed using a $35 \mathrm{~mm}$ Nikon ${ }^{\circledR}$ FM camera with a $35-210 \mathrm{~mm}$ lens. To minimize systematic errors, the lens of the camera was kept within one to two degrees of perpendicular to the bole of the tree at DBH by placing a carpenter's level on the camera lens.

Because these photographs were such an integral part of the data collection, the distortion of the camera and lens were investigated. Following the same techniques used in collection of tree crown data photographs, objects of known size (a building) were photographed and relative distortion was calculated. 
This method for testing the distortion of the camera actually tested the distortion associated with the entire processing stage. The distortion reported here could be attributed to the lens or the camera, but also to the film processing to acquire the negatives and the scanning of the negatives. It was found that the overall average relative distortion of camera and lens was just over 3\%, with a high of $14 \%$. Distortion occurred in all regions of the photograph, but was slightly higher toward the edges. These errors are within acceptable limits and are probably smaller than would be found using other nondestructive methods. With the Criterion Laser ${ }^{\circledR}$ used by Biging and Gill (1997) there is a problem with wind induced movement of trees during the data collection process, which introduces error. Also, there is no way with their method to verify the measurements recorded in the field, whereas the photographs used in this project can be checked at a later time. For a more complete description of the camera distortion refer to Gill (1997).

\section{METHODS}

\subsection{Processing of Data}

The negatives of the photographs were scanned using a Nikon Coolscan ${ }^{\circledR}$ scanner. The scale of each photograph was determined from field measurements of tree height using the ratio of tree height measured on the image to actual tree height. The average scale of these scanned images was $0.025 \mathrm{~m}(0.082 \mathrm{feet})$ per picture element (pixel) with a standard deviation of $0.0125 \mathrm{~m}$ ( $0.041 \mathrm{feet})$ and a range from $0.0046 \mathrm{~m}$ ( 0.015 feet $)$ per pixel to $0.062 \mathrm{~m}$ (0.204 feet) per pixel. At least one profile of each of these scanned images was then screen digitized using ERDAS ${ }^{\circledR}$ (ERDAS 1991) to acquire $x$ - $y$ coordinates of locations along the crown profile that could then be converted to height-radius pairs. When taking these measurements, the exterior of the crown profile was measured. The crown profile had to satisfy a functional relationship such that crown radius was a function of height. This meant that a given height value could have no more than one crown radius measurement. At a particular height, if it was possible to measure the crown radius at more than one location because of the branching patterns, only the point furthest from the tree bole was measured (refer to points A and B in Figure 1, panel 1a). Any profiles that were digitized had to be clearly visible on the photograph. In most instances only one profile (either the left or right profile) was measured from photographs. However, in a small number of cases it was possible to clearly see both the left and right profiles of the crown, in which case both sides were measured and used in the analysis. When making these measurements the crown was measured from the center of and perpendicular to the bole of the tree to the exterior of the crown.

When digitizing these tree crown profiles, it was sometimes difficult to clearly distinguish the edge of the tree crown from shadows of other branches or other trees or to distinguish the tree crown being digitized from a crown behind the subject tree. We used digitial image contrast enhancement to maximize the contrast of trees on the scanned images and we simultaneously viewed color photographs under magnification to assist us in 
digitizing the selected tree profiles. In the photographing stage of data collection every effort was made to obtain photos in which a good contrast between a crown profile and the open sky could be obtained.

Instead of having a function that changes over time, as in most time-series analysis, the radii of tree crowns were considered as functions of the height increment. Thus, height increment was analogous to the time variable in standard time-series analysis.

The analysis of time-series data is facilitated by equidistant measurements. Following the techniques of Biging and Gill (1997) to achieve equidistant measurements, a natural cubic spline (Cheney and Kincaid 1985) was fit to the data and crown radii measurements were interpolated to exact 0.15 or 0.3 meters (one-half foot or one foot) intervals dependent on the length of the tree crown. In their study, Biging and Gill (1997) used 0.3 or $0.6 \mathrm{~m}$ (one or two foot) intervals. In this study we were able to interpolate to smaller increments than Biging and Gill (1997) because we could make finer measurements from the photographs than was possible using the Criterion laser. For trees with crown lengths less than 12.2 $\mathrm{m}$ (40 feet), $0.15 \mathrm{~m}$ (one-half foot) intervals were used and for trees with crown lengths greater than $12.2 \mathrm{~m}$ (40 feet) $0.3 \mathrm{~m}$ (one-foot) intervals were used. For these series, the average number of digitized points and interpolated points were $121.2(\sigma=31.2)$ and $58.0(\sigma=14.3)$, respectively. The average ratio ( $\mathrm{R})$ of digitized to interpolated points was $2.13\left(\sigma_{\mathrm{R}}=0.63\right)$ with a minimum of 0.88 . If the data changed erratically, the cubic spline would sometimes not adjust quickly enough and would swing away from the data. When this situation was encountered, an adjustment was made to the spline function using linear interpolation.

\subsection{ARMA Models}

When analyzing time-series data, it is desirable to have a stationary series because much of the inference involved in the analysis requires stationarity. A covariance stationary series is one with a constant mean (no trend) and homogeneous variance. Plots of the data revealed that all series contained a trend, which would have to be modeled. When analyzing series that are not stationary, there are different approaches that may be applied. Two such approaches, discussed below, are Method 1: to first remove the trend and then fit ARMA models to the residuals, or Method 2: to simultaneously fit a regression model with ARMA errors.

With the first approach one can use any suitable trend line, but typically the trend is a low order polynomial or trigonometric polynomial estimated with OLS (this is referred to as global least squares in time series literature). Other selections for trend models include a grafted polynomial model where each polynomial fits a subsection of the series or a moving average model (Fuller 1996). The estimates of the standard errors for the trend coefficients may be biased if the trend removal was done using OLS (Fuller 1996) and that is a drawback of this approach. However, with large sample sizes, the bias approaches zero.

After the trend is removed, ARMA models can be fit to the model using the techniques 
of Box and Jenkins (1970). The form of an $\operatorname{ARMA}(p, q)$ is:

$$
z_{t}=\phi_{1} z_{t-1}+\phi_{2} z_{t-2}+\cdots+\phi_{p} z_{t-p}+\delta+u_{t}-\theta_{1} u_{t-1}-\cdots-\theta_{q} u_{t-q}
$$

where

$$
\begin{aligned}
z_{t}= & \text { residuals from trend removal }(t=1, \ldots, T) \\
\phi_{i}= & \text { parameters of the autoregressive factors }(i=1, \ldots, p) \\
\theta_{k}= & \text { parameters of the moving average factors }(k=1, \ldots, q) \\
\delta= & \text { constant; and } \\
u_{t}= & \text { white noise (a sequence of identically and independently distributed random distur- } \\
& \text { bances with mean zero and variance } \left.\sigma^{2}\right) \text { (Nelson 1973). }
\end{aligned}
$$

All the identification techniques, such as the autocorrelation function (ACF) and the partial autocorrelation function (PACF) can be applied to the residuals after removal of the trend. ARMA diagnostic techniques may also be applied to these models. The approach of first removing the trend is appropriate when one is primarily interested in identifying and estimating the appropriate ARMA model for the residuals around a trend (Fuller 1996)

The second approach simultaneously fits a regression (trend line) with ARMA errors. Many statistical packages will fit a regression model with autoregressive errors (SAS, SPSS, S-Plus, and STATA). A subset of these statistical packages (SPSS, S-Plus, and STATA) will fit a regression model with ARMA errors by simply specifying the dependent variable, independent variables, and the order of the ARMA parameters. It is possible to determine the most appropriate ARMA model for either approach by using likelihood ratio tests or the Bayesian information criterion.

We performed a test comparing Method 1 and 2 on a $10 \%$ subset of our data. Although there are theoretical benefits for simultaneously fitting the model, we found no practical differences in terms of the trend coefficients, the ARMA model coefficients and the standard errors of the ARMA coefficients. Thus, for this project we selected Method 1: fitting a simple polynomial trend with OLS and then modeling the resultant residuals using ARMA. We did this for the following reasons: (1) both methods produced similar results, (2) most researchers have only fit a trend model to tree crown profiles, so our interest was primarily in estimating the signal in the residuals around this line, and (3) we did not need to conduct hypothesis tests of the trend coefficients, so improved estimation of their variances was not a focus of this article.

Simple polynomial trends which produced familiar crown profiles (conic, parabolic) were selected for detrending the series because most researchers stop their modeling efforts after fitting one of these models via OLS. Our modeling effort essentially started where most prior tree crown modeling efforts have stopped. Biging and Gill (1997) pointed out that, when using this approach, these models can be viewed as having three components: (1) a trend line; (2) an ARMA component; and (3) random error. By fitting the models following a two-step approach it was possible to examine each of these three components separately.

Two standard tools, which aid in the identification of the appropriate ARMA model, the 
autocorrelation function (ACF) and the partial autocorrelation function (PACF) were plotted. After tentative models were selected by examining the ACF and the PACF, the model parameters were estimated using conditional least squares estimation. In addition, since the ACF and the PACF do not often give a clear indication as to the appropriate model for the crown profiles series investigated, 15 models were estimated for each series (ARMA $(p, q)$, with $(p, q) \in\{(1,0),(2,0),(3,0),(0,1),(0,2),(0,3),(1,1),(2,1),(1,2),(2,2),(3,1),(1,3)$, $(3,2),(2,3),(3,3)\})$. Note that an $\operatorname{ARMA}(p, 0)$ is equivalent to an $\operatorname{AR}(p)$ and an $\operatorname{ARMA}(0, q)$ is equivalent to an $\operatorname{MA}(q)$. A more general criterion for model selection (not limited to the time series context) is found by minimizing Akaike's information criterion (AIC) (Akaike 1971, 1974), modified to penalize models with many parameters. This later adaptation is called the Bayesian modification of AIC, or BIC (Akaike 1978, 1979). The BIC, like other alternative selection criterion, assumes data normality and can lead to more than one minimum. As such, these criteria should be used as guides to model selection. The form of the BIC used in this study was (Chatfield 1989):

$$
\mathrm{BIC}=T * \ln \left(\frac{\mathrm{RSS}}{T}\right)+(p+q+m+1)+(p+q+m) * \ln (T),
$$

where

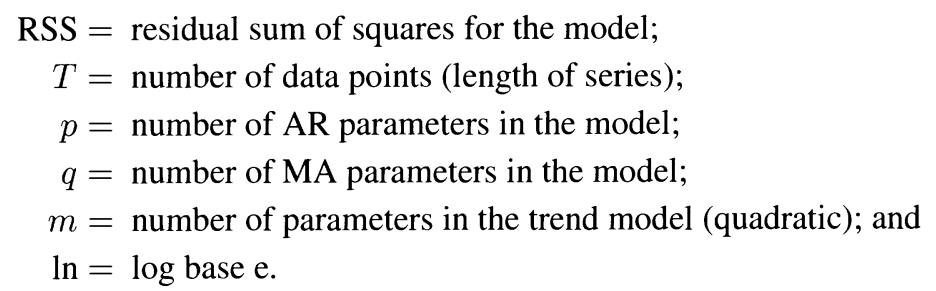

When using this criterion, the model with the smallest BIC is presumed to be the best model. But since the BIC is only a guide to model selection we specified that any model that was within 5\% (value arbitrarily selected) of the smallest BIC was equally as viable a model as the one with the minimum BIC.

\subsection{Classification of Models}

After trends were removed and ARMA models fit to each series, a classification scheme was used to determine if the type of ARMA model appropriate for a given tree was related to species, size of tree, or stand density. Before this could be done, we needed to identify one appropriate model for each tree based on the rankings of the BIC in conjunction with the ACF and PACF functions. The classes used in the classification and regression trees (CART) analysis included: AR(1), MA(1), AR(0), and "nonstationary." We did not include higher order models in this analysis because a large majority of the trees could be modeled using these low-order models, and because ultimately we desire to predict the trend and ARMA coefficients from tree and stand parameters. Clearly, it is desirable to minimize the total number of parameters for this venture. Series were identified as these models only if the 
BIC was within 5\% of the smallest and the coefficients were significant. This categorizing was for trees in which the removal of the trend produced a stationary series. Stationarity was determined from visual examination of the residual series (after removal of the trend) and by testing the significance of the $\mathrm{AR}(1)$ terms using the $t$ statistic (note that an $\mathrm{AR}(1)$ series is stationary if $\left|\phi_{1}\right|<1$ ). Series in which the removal of a trend did not produce a stationary series were identified as a "nonstationary" class. Models were ranked with MA(1) as the best followed by an AR(1) and then a AR( 0$)$ model. This ranking was selected because the MA(1) model essentially requires one less parameter than does the AR(1) model (i.e., the $\mathrm{AR}(1)$ model required the crown radius at the height-to-crown base, whereas the MA(1) model did not). The identification of time-series models for individual crown series was done using the following rules:

1. a tree for which the BIC of the MA(1) model was within 5\% of best was identified as an MA(1) model;

2. a tree for which the BIC of both the AR(1) model and the MA(1) was within 5\% of the best was also identified as an MA(1);

3. a tree for which the BIC of the AR(1) model was within $5 \%$ but the BIC of the MA(1) model was not within 5\% was identified as an AR(1); and

4. all other trees were identified as an $\operatorname{AR}(0)$ model.

After each series had been identified as an MA(1), AR(1), AR(0) model, or "nonstationary," a classification scheme was developed based on tree and stand characteristics using classification and regression trees (CART). CART is a binary tree classification in which a classification is constructed by repeated splits of subsets of the data in two new subsets, beginning with the entire dataset (Breiman, Friedman, Olshen, and Stone 1984). CART was used instead of discriminant analysis because the assumptions of multivariate normal distributions and equal covariance matrices required for discriminant analysis could not be met with this dataset. CART was also selected because of the ease of including categorical variables such as species and because of the simplicity of interpretation. Since each split in CART is based on specific values of variables (e.g., diameter less than $40 \mathrm{~cm}$ ), the results are easy to interpret. Large classification trees were grown with CART and were then pruned to achieve a more efficient classification tree.

Because of the large expense and difficulty of collecting the base data, it was not possible in this project to collect an independent validation dataset. Instead, cross-validation was used to determine the level to which the classification trees should be pruned. Competing CART trees may be compared by examining the rate of misclassification and the reduction in misclassification with the inclusion of an additional split.

\section{RESULTS AND DISCUSSION}

\subsection{ARMA Models}

The first step in the analysis was to detrend the series. For $95 \%$ of the trees in this study, removal of a quadratic trend was sufficient to produce a stationary series. Neither the removal of a quadratic or a cubic trend were sufficient for producing stationary series for 
Table 2. Model Types With the Smallest BIC

\begin{tabular}{|c|c|c|}
\hline Model type & $\begin{array}{c}\text { No. of series where this model } \\
\text { type has the smallest BIC }\end{array}$ & $\begin{array}{l}\text { No. of series where this model } \\
\text { has smallest BIC or is within } 5 \% \text { of smallest BIC }\end{array}$ \\
\hline $\mathrm{AR}(0)$ & 54 & 54 \\
\hline $\mathrm{AR}(1)$ & 94 & $122^{a}$ \\
\hline $\mathrm{AR}(2)$ & 0 & 11 \\
\hline $\mathrm{AR}(3)$ & 0 & 6 \\
\hline $\mathrm{MA}(1)$ & 63 & $93^{b}$ \\
\hline $\mathrm{MA}(2)$ & 5 & 23 \\
\hline $\mathrm{MA}(3)$ & 2 & 7 \\
\hline $\operatorname{ARMA}(1,1)$ & 1 & 18 \\
\hline $\operatorname{ARMA}(1,2)$ & 0 & 6 \\
\hline $\operatorname{ARMA}(1,3)$ & 0 & 1 \\
\hline $\operatorname{ARMA}(3,2)$ & 0 & 1 \\
\hline $\operatorname{ARMA}(3,3)$ & 0 & 3 \\
\hline total & 219 & \\
\hline
\end{tabular}

the other 5\% of the trees and so they were not modeled as ARMA processes. For stationary series, the ARMA models were then fit to the residuals around the trend. Because the timeseries models were fit to the residuals of the trend removal, statistically significant ARMA models were a de facto improvement over using simple geometric forms.

Models for which the coefficients were significant and the BIC was within 5\% of the smallest BIC were judged to be nearly optimal and thus acceptable. It was found that 122 of 219 conifer series could be modeled as an AR(1) (see Table 2). Of these 122 series, there are 54 for which the $\mathrm{MA}(1)$ was also within $5 \%$ of the best. There were an additional 39 (for a total of 93) series that could be modeled as an MA(1). Qualitatively an AR(1) and an MA(1) result in similar crown profiles simulations (Biging and Gill 1997). This is not surprising considering an $\mathrm{AR}(1)$ can be written as an infinite MA process and can be approximated by a relatively small order MA process (if the coefficients are small) and vice versa (Box and Jenkins 1970).

When these ARMA models were used to simulate tree crown profiles, realistic profiles were created. As examples of the simulation, Figure 1 (p. 561) shows the actual crown profile and two simulations using an MA(1) process and two simulations using an AR(1). These simulations are realistic and visually they provide an improvement over a simple Euclidean model. As with Biging and Gill (1997) we found that the AR(1) and the MA(1) simulations were qualitatively similar.

\subsection{Classification of Models}

To develop a classification and regression tree (CART), it was necessary to associate each tree with one and only one model form. This association was done by using only first order models $[\mathrm{AR}(1)$ and $\mathrm{MA}(1)]$ along with the $\mathrm{AR}(0)$, with preference given to an MA(1) if both first order models were appropriate. Using this association, it was found 


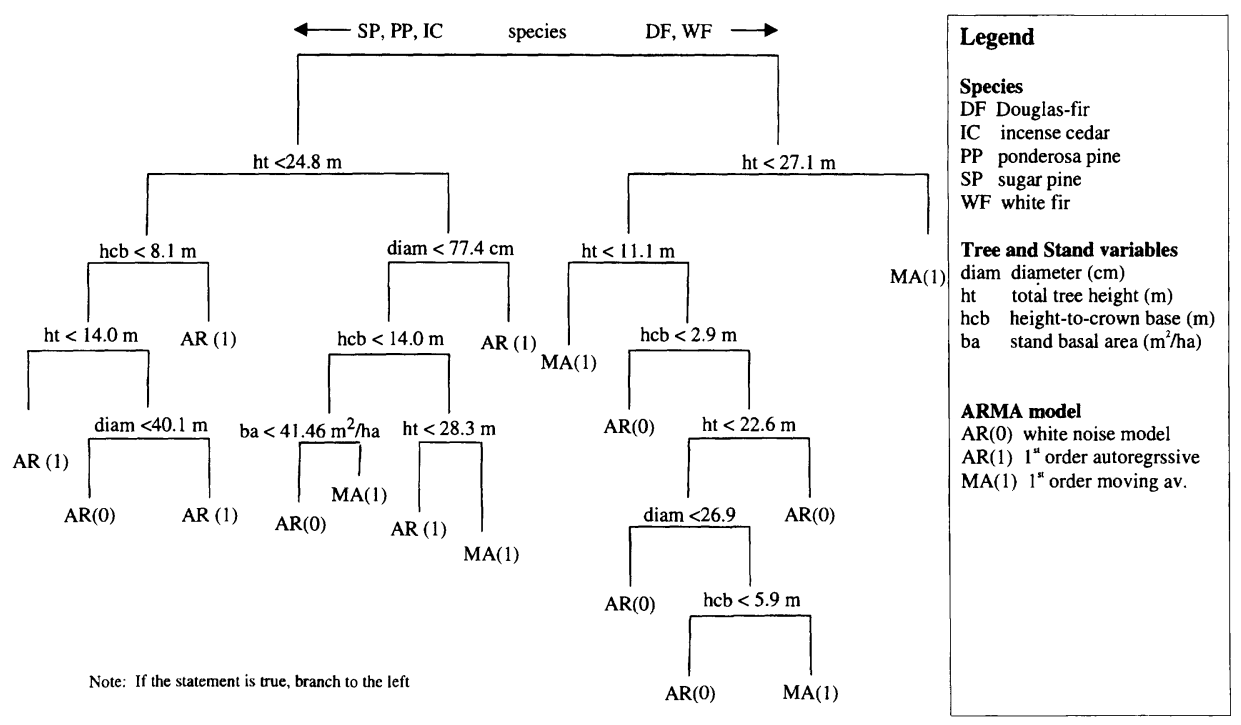

Figure 2. CART classification scheme for determining which ARMA model to use on a specific conifer tree.

that $93(42 \%)$ of the series could be modeled as an MA(1), $59(27 \%)$ as an $\operatorname{AR}(1), 57$ $(26 \%)$ as an $\mathrm{AR}(0)$ and the remaining $10(5 \%)$ were not stationary after the removal of the quadratic trend. Thus, roughly $70 \%$ of the conifer series (152/219) could be modeled using first-order ARMA models. This was similar to the $80 \%$ that Biging and Gill (1997) found in a pilot study. However, the dataset used in this project is significantly larger than that used by Biging and Gill (1997) and samples are taken over a broader geographical region and include a larger range of tree sizes and forest stand densities.

The classification tree (from CART) for determining which type of ARMA model should be used is shown in Figure 2. When interpreting this figure, if the statement is true follow the branch to the left and if it is false follow the branch to the right. This classification tree had 16 terminal nodes and uses species, diameter, height, height-to-crown base, and stand basal area in the classification. The first split of the classification tree was based on species and is approximately a split along shade tolerance of these species. This classification never modeled Douglas-fir or white fir using an AR(1) model. Ponderosa pines, sugar pines, and incense cedar trees less than $24.8 \mathrm{~m}$ ( $81.5 \mathrm{feet})$ in height were never modeled as an MA(1) process. The only stand variable used in this classification tree was a density measure, basal area $\left(\mathrm{m}^{2} / \mathrm{ha}\right)$, and it was only used for one split. It is interesting to note that diameter and height were used frequently for splitting, whereas only one of the crown parameters (height-to-crown base) was used in the classification. Surprisingly, crown radius was not useful in predicting the type of ARMA model that should be used for modeling an individual tree crown profile.

The nonstationary category was never selected in this classification, but it accounted for only $5 \%$ of the profiles. The overall misclassification rate from cross-validation for this classification tree was $36.5 \%$ (see Table 3 ). The forces influencing tree crowns include tree 
Table 3. Confusion matrix for the CART analysis of the ARMA models

\begin{tabular}{|c|c|c|c|c|c|c|}
\hline \multirow{2}{*}{$\begin{array}{l}\text { Actual } \\
\text { Model }\end{array}$} & \multicolumn{3}{|c|}{ Predicted model } & \multirow{2}{*}{$\begin{array}{c}\text { Non- } \\
\text { stationary }\end{array}$} & \multirow{2}{*}{$\begin{array}{c}\text { Row } \\
\text { totals }\end{array}$} & \multirow{2}{*}{$\begin{array}{l}\text { User's } \\
\text { acc.\% }\end{array}$} \\
\hline & $A R(0)$ & $A R(1)$ & $M A(1)$ & & & \\
\hline $\mathrm{AR}(0)$ & 42 & 3 & 12 & 0 & 57 & 73.7 \\
\hline$A R(1)$ & 6 & 38 & 15 & 0 & 59 & 64.4 \\
\hline$M A(1)$ & 19 & 15 & 59 & 0 & 93 & 63.4 \\
\hline Nonstationary & 3 & 4 & 3 & 0 & 10 & 00.0 \\
\hline Total & 70 & 60 & 89 & 0 & 219 & \\
\hline \multirow[t]{2}{*}{ Producer's acc. \% } & 60.0 & 65.0 & 67.4 & 0.0 & & \\
\hline & & & & & & $\begin{array}{c}\text { Overall acc.\% } \\
63.5\end{array}$ \\
\hline
\end{tabular}

and stand effects as well as microenvironment effects. These later effects cannot be readily quantified, but will add to misclassification error. There is no comparative work to suggest whether the approximate 1/3 misclassification rate is high or low. The user's accuracy for the $\operatorname{AR}(0)$ classification is nearly $75 \%$, thus yielding fairly reliable results for this class. The AR(1) and MA(1) user's accuracies were approximately 10 percentage points lower than for the $\mathrm{AR}(0)$ model. The misclassification from the AR(1) model was primarily with the MA(1) model and vice versa, although there was also confusion between MA(1) and $\mathrm{AR}(0)$. If one combines the $\mathrm{AR}(1)$ and MA(1) class, the user's accuracy is approximately $84 \%$. From a simulation perspective the $\mathrm{AR}(1)$ and $\mathrm{MA}(1)$ model are functionally and qualitatively similar. The only penalty for misclassifying an MA(1) model as an AR(1) model comes from the need to estimate one additional parameter. We view the overall classification results as achieving acceptable accuracy.

\section{CONCLUSIONS}

This project analyzed conifer crown profiles sampled from a wide range of tree sizes and stand densities. For the profiles studied, $70 \%$ could be modeled as trend lines plus statistically significant first order ARMA models and another $25 \%$ as trend lines plus white noise models $(\mathrm{AR}(0))$. The results confirm that the methods developed by Biging and Gill (1997) are more broadly applicable for conifer forests sampled throughout northern California. These time-series models were found to be visually an improvement over simple geometric forms. Because the coefficients were significant, they were statistically an improvement over using simple Euclidean geometric forms.

Even though a trend line and ARMA model provided improvements in describing conifer tree crown profiles, it would be impracticable to collect the very detailed crown data used in this study to parameterize these models for every individual tree. Thus, a second goal of this research was to examine if the order of the ARMA model can be predicted from readily observable forest and tree characteristics gathered in a forest survey data (e.g., diameter, height, species, basal area). Hence, we used a binary classification technique, to develop classification rules for specifying the type of model [MA(1), AR(1), or AR(0)] that 
can be appropriately used for simulating the profile of a specific individual tree. The overall classification accuracy of this classification was approximately $65 \%$.

Using the CART classification to specify the type of ARMA model needed for an individual tree is the first step needed for crown profile prediction. The second step is to predict the trend line and ARMA model parameters, once the type of ARMA model has been specified. This second step will be reported in a future study. Using this two-step prediction approach we will then be able to generate crown profiles for all measured trees surveyed in this forest type, not solely those chosen in this research initiative. Then it will become feasible for forest managers and scientists to routinely use these methods to generate realistic crown profiles. Crown information is particularly useful in managing the aesthetics of forest views, in characterizing wildlife habitat, in projecting individual tree growth, and characterizing competition between neighboring trees.

\section{ACKNOWLEDGMENTS}

The authors thank John Rice, Department of Statistics, UC Berkeley for valuable statistical advice on timeseries analysis used in this project. They are also grateful to Edward Murphy and Dan Tomacheski of Sierra Pacific Industries and Bob Heald at the University of California's Blodgett Forest Experiment Station for providing access to forest lands and information needed for conducting this study. We also thank Robert Monserud and Keith Gilless for reviewing early versions of this article and the anonymous reviewers for their considered reviews. This research was partially funded by McIntire-Stennis projects 6154-MS and 5259-MS.

\section{REFERENCES}

Akaike, H. (1971), "Information Theory and an Extension of the Maximum Likelihood Principle," Research Memorandum No. 46, Institute of Statistical Mathematics Tokyo, in 2nd International Symposium On Information Theory, eds. B.N. Petrov and F. Csaki, Budapest: Akademiai Kiade, pp. 267-281.

(1974), "A New Look at the Statistical Model Identification," IEEE Transactions on Automatic Control, AC-19, 716-722.

(1978), “A Bayesian Analysis of the Minimum AIC Procedure," Annals of the Institute of Statistical Mathematics, 30A, 9-14.

(1979), "A Bayesian Extension of the Minimum AIC Procedure of Autoregressive Model Fitting," Biometrika, 66, 237-242.

Assmann, E. (1970), The Principles of Forest Yield Study; Studies in the Organic Production, Structure, Increment, and Yield of Forest Stands, New York: Pergamon Press.

Baldwin, V. C. J., and Paterson, K. D. (1997), "Predicting the Crown Shape of Loblolly Pine Trees," Canadian Journal of Forest Research, 27, 102-107.

Biging, G. S., and Dobbertin, M. (1992), "A Comparison of Distance-Dependent Competition Measures for Height and Basal Area Growth of Individual Conifer Trees," Forest Science, 38, 695-720.

377.

Biging, G. S., and Gill, S. J. (1997), "Stochastic Models for Conifer Tree Crown Profiles," Forest Science, 43, 25-34. 
Biging, G. S., and Wensel, L. C. (1990), "Estimation of Crown Form for Six Conifer Species of Northern California," Canadian Journal of Forest Research, 20, 1137-1142.

Box, G. E. P, and Jenkins, G. M. (1970), Time-Series Analysis: Forecasting and Control, San Francisco: HolderDay.

Breiman, L., Friedman, J. H., Olshen, R. A., and Stone, C. J. (1984), Classification and Regression Trees, Monterey, CA: Wadsworth and Brooks/Cole Advanced Books and Software.

Burkhart, H. E. (1992), "Scientific Visualization for the Study and Use of Forest Stand Simulators," Landscape and Urban Planning, 21, 317-318.

Chatfield, C. (1989), The Analysis of Time Series: An Introduction, London, Chapman and Hall.

Cheney, W., and Kincaid, D. (1985), Numerical Mathematics and Computing, Monterey, CA: Brooks/Cole Publishing.

Colin, F., and Houllier, F. (1992), "Branchiness of Norway Spruce in Northeastern France: Predicting the Main Crown Characteristics from Usual Tree Measurements," Annales des Sciences Forestieres (Paris), 49, 511 538.

Corona, P. (1991), "Studying Tree Crown Architecture by Fractal Analysis," Italia Forestale E Montana, 46, 291-307.

Doruska, P. F., and Mays, J. E. (1998), "Crown Profile Modeling of Loblolly Pine by Nonparametric Regression Analysis," Forest Science, 4, 445-453.

Dong, P. H., and Kramer, H. (1986), "Auswirkungen von Umweltbelastungen auf das Wuchsverhalten verschiedener Nadelbaumarten im nordwestdeutschen Küstenraum,” Der Forst-und Holzwirt , 41, 286-290.

ERDAS (1991), ERDAS Field Guide, Atlanta, GA: Author.

Ford, E. D., Avery, A., and Ford, R. (1990), "Simulation of Branch Growth in the Pinaceae: Interactions of Morphology, Phenology, Foliage Productivity, and the Requirement for Structural Support, on the Export of Carbon," Journal of Theoretical Biology, 146, 15-36.

Ford, R. and Ford, E. D. (1990), "Structure and Basic Equations of a Simulator for Branch Growth in the Pinaceae," Journal of Theoretical Biology, 146, 1-13.

Fuller, W. A. (1996), Introduction to Statistical Time Series (2nd ed.), New York: Wiley.

Gavrikov, V. L., and Karlin, I. V. (1992), "A Dynamic Model of Tree Terminal Growth," Canadian Journal of Forest Research, 23, 326-329.

Gill, S. J. (1997), "Stochastic Models of Tree Crown Profiles," unpublished Ph.D. Dissertation, University of California, Berkeley.

Gill, S. J., and Biging, G. S. (2002), "Autoregressive Moving Average (ARMA) Models of Crown Profiles for two California Hardwood Species," Ecological Modelling, 152, 213-226.

Hann, D. W. (1999), “An Adjustable Predictor of Crown Profile for Stand-Grown Douglas-fir Trees," Forest Science, 45, 217-225.

Jordan, D. N., and Lockaby, B. G. (1990), "Time Series Modeling of Relationships Between Climate and LongTerm Radial Growth of Loblolly Pine," Canadian Journal of Forest Research, 20, 738-742.

Kershaw, J. A., and Maguire, D. A. (1996), "Crown Structure in Western Hemlock, Douglas-fir, and Grand Fir in Western Washington: Horizontal Distribution of Foliage Within Branches," Canadian Journal of Forest Research, 26, 128-142.

Kramer, H. (1988), Waldwachstumslehre: Ökologische und anthropogene Einflüsse auf das Wachstum des Waldes, seine Massen-und Wertleistung und die Bestandessicherheit, Hamburg: Parey, Hans-Achim Gussone.

Kuuluvainen, T., and Pukkula, T. (1989), "Simulation of Within-tree and Between-tree Shading of Direct Radiation in a Forest Canopy: Effects of Crown Shape and Sun Elevation,” Ecological Modeling, 49, 89-100.

Maguire, D. A., Moeur, M., and Bennett, W. S. (1994), "Models for Describing Basal Diameter and Vertical Distribution of Primary Branches in Young Douglas-fir," Forest Ecology and Management, 63, 23-55.

Mawson, J. C., Thomas, J. W., and DeGraff, R. M. (1976), "Program HTVOL The Determination of Tree Crown Volume by Layers," USDA Forest Service Research Paper NE-3549. 
McGaughey, R. J. (1998), “Techniques for Visualizing the Appearance of Forestry Operations,” Journal of Forestry, 96, 9-14.

Mitchell, K. J. (1975), “Dynamics and Simulated Yield of Douglas-fir,” Forest Science Monograph, 17.

Moeur, M. (1981), "Crown Width and Foliage Weight of Northern Rocky Mountain Conifers," USDA Forest Service Research Paper INT-283.

Mohren, G. M. J., Gerwen, C. P. V., and Spitters, C. J. T. (1984), "Simulation of Primary Production in Even-aged Stands of Douglas-fir," Forest Ecology and Management, 9, 27-49.

Monserud, R. A. (1986), “Time-Series Analysis of Tree-ring Chronologies,” Forest Science, 32, 349-372.

Morrison, M. L., Timossi, I. C., and With, K. A. (1987), "Development and Testing of Linear Regression Models Predicting Bird-habitat Relationships,” Journal of Wildlife Management, 51, 247-253.

Nagel, J. (2001), "BWINPRO: Program for Stand Analysis and Prognosis. User's Manual for Version 6.02," Abteilung Waldwahstum. Niedersächsische Forstliche Versuchsanstalt, 87.

Nepal, S. K., Somers, G. L., and Caudill, S. H. (1996), "A Stochastic Frontier Model for Fitting Tree Crown Shape in Loblolly Pine (Pinus taeda L.)," Journal of Agricultural, Biological, and Environmental Statistics, 1, 336-353.

Nelson, C. R. (1973), Applied Time Series Analysis for Managerial Forecasting, San Francisco, Holden-Day Inc.

Pretzsch, H. (1992), "Modellierung der Kronenkondurrenz von Fichte und Buche in Rein- und Mischbeständen," in Allgemeine Forst-und Jagdzeitung 163, 11-12, 203-213.

(1993), Analyse und Reproduktion räumlicher Bestandesstrukturen. Versuche mit dem Strukturgenerator STRUGEN, Schriften aus der Forstlichen Fakultät der Universität Göttingen und der Niedersächsischen Forstlichen Versuchsanstalt, Band 114, Sauerländer's Verlag.

StataCorp. (1999), Stata Statistical Software: Release 6.0, College Station, TX: Stata Corporation.

SAS Institute Inc. (1999), SAS/STAT User's Guide, Release 8.0. Cary, NC: SAS Institute Inc.

S-Plus (2000), Guide to Statistics, volumes 1-2, Seattle, WA: Data Analysis Products Division, MathSoft.

SPSS Inc. (1995), SPSS Release 6.1.1., Chicago, IL.

Zeide, B. (1998), "Fractal Analysis of Foliage Distribution in Loblolly Pine Crowns," Canadian Journal of Forest Research, 28, 106-114.

Zeide, B., and Gresham, C. A. (1991), "Fractal Dimensions of Tree Crowns in Three Loblolly Pine Plantations of Coastal South Carolina," Canadian Journal of Forest Research, 21, 1208-1212.

Zeide, B., and Pfeifer, P. (1991), "A Method for Estimation of Fractal Dimension of Tree Crowns," Forest Science, $37,1253-1265$. 